\title{
Política e ideología en el sistema escolar de la transición a la democracia en Chile en sus debates sobre género y sexualidad
}

Politics and ideology in the schooling system of the transition to democracy in Chile in its debates on gender and sexuality

\author{
Sebastián Neut Aguayo* \\ Daniela Luque Carmona** \\ Dominique Méndez Mardones***
}

\begin{abstract}
Resumen: Una de las principales demandas del movimiento feminista que se ha manifestado desde 2018 ha sido la de proveer una "educación no sexista", indicando con ello que el sistema escolar estaría permeado por lógicas patriarcales. El presente artículo tiene como objetivo aportar en la comprensión de tal problema, a partir de una mirada a sus antecedentes recientes. En concreto, pretende dar una visión sintética al desarrollo político e ideológico de las principales políticas asociadas a sexualidad y género en el contexto de transición a la democracia en Chile (1988-1998).
\end{abstract}

Palabras clave: Movimiento feminista, educación no sexista, patriarcalismo, políticas de género

\begin{abstract}
One of the main demands of the feminist movement that has manifested since 2018 has been to provide a "non-sexist education", indicating that the school system would be permeated by patriarchal logic. This article aims to contribute to the understanding of this problem, based on a look at its recent background. Specifically, it aims to give a synthetic vision to the political and ideological development of the main policies associated with sexuality and gender in the context of transition to democracy in Chile (1988-1998).
\end{abstract}

Keywords: Feminist movement, non-sexist education, patriarchalism, gender policies

Recibido: 4 abril 2019 Aceptado: 9 agosto 2019

* Chileno, coautor, estudiante de Doctorado en Educación Katholieke Universiteit Leuven, sgneut@uc.cl.

** Chilena, coautora, estudiante de magíster en Estudios Latinoamericanos Universidad de Chile, docente Facultad de Educación Universidad Diego Portales, daniela.luque@mail.udp.cl.

*** Chilena, coautora, estudiante de Pedagogía en Educación Básica, Pontificia Universidad Católica de Chile, damendez@uc.cl. 


\section{Introducción}

Respecto del contexto y tema estudiados, se ha avanzado en la comprensión del movimiento social feminista ${ }^{1}$; de las políticas públicas (no escolares) con perspectiva de género ${ }^{2}$; de la influencia de la Iglesia católica sobre políticas sexuales ${ }^{3}$, y de los vínculos que se pueden rastrear entre género, sexualidades y una nueva visión de la nación ${ }^{4}$. Respecto de la literatura que da cuenta de las políticas educacionales en el contexto estudiado, un artículo de Elizabeth Guerrero (et. Al.) estudia el desarrollo de estas a nivel gubernamental durante la década de 19905, mientras que la tesis de Leonardo Arenas describe las políticas en educación sexual entre 1990 y 20146. Si bien ambas resultan insumos centrales en el desarrollo del presente trabajo, creemos que se requiere de un estudio que ponga en relieve las formas de articulación e implementación política en su vínculo con los debates ideológicos acaecidos. Al respecto, el presente texto pretende generar una nueva lectura histórica del contexto y temas estudiados a partir de la adición de nuevos registros documentales.

Aunque estudiamos las políticas en sexualidad y género, el artículo no se sitúa estrictamente en los estudios de género -es más 'sobre' que 'de' género-, aunque se valga libremente de sus valiosos aportes. Más bien se posiciona en la línea de una historia sociopolítica de la educación. Ello pues creemos que, para un análisis sociopolítico, "necesitamos teorías y conceptos intermediarios que, sin abandonar esquemas interpretativos como el control social, la dominación y la disciplina resulten lo bastante sutiles y narrativos como para permitir una historia de la educación contextualizada y sin reduccionismos"7. La misma alerta conceptual podría ser atribuida a la categoría inicialmente mencionada.

Es importante considerar que, en la medida en que el sistema escolar remite al "discurso moral que crea orden, relaciones e identidad" 8 , resulta un espacio de enorme sensibilidad sociopolítica, lo que lo convierte en un privilegiado campo en disputa por su control y legitimación ${ }^{9}$. En relación a tal suposición planteamos que se produjo una especie

1 Marcela Ríos Tobar y Lorena Godoy, ¿Un nuevo silencio feminista?: la transformación de un movimiento social en el Chile posdictadura, Centro de Estudios de la mujer, Santiago, Editorial Cuarto Propio, 2003.

2 Patricia Díaz, El género de la transición. Una historia de las políticas públicas con perspectiva de género en los gobiernos de la Concertación, Memoria para optar al título profesional de Periodista, Santiago de Chile, Universidad de Chile, 2012.

3 José Morán, "Feminismo, Iglesia católica y derechos sexuales y reproductivos en el Chile post-dictatorial", Estudios Feministas, 21:2, Florianópolis, 2013, 485-508.

4 Carmen Godoy Ramos, Géneros, Sexualidad/es y Nación en el Chile Postdictatorial 1990-2008, Tesis para optar al grado de Doctora en Estudios Latinoamericanos, Santiago de Chile, Universidad de Chile, 2011.

5 Elizabeth Guerrero Caviedes, Patricia Provoste Fernández y Alejandra Valdés Barrientos, "La desigualdad olvidada: género y educación en Chile", Equidad de género y reformas educativas, Santiago de Chile, Hexagrama Consultoras, FLACSO, Instituto de Estudios Sociales Contemporáneos, 2006.

6 Leonardo Arenas, Historia de la educación sexual en chile (1990-2014): enfoques y perspectivas, Tesis para optar al grado de Magíster en Educación, Santiago de Chile, Universidad Academia de Humanismo Cristiano, 2015.

7 Marc Depaepe, Vieja y nueva historia de la educación, ensayos críticos, Barcelona, Octaedro, 2006, p. 41.

8 Basil Bernstein, Pedagogía, control simbólico e identidad, Madrid, Morata, 1996, p. 92.

9 Raymond Williams, La larga revolución, Buenos Aires, Nueva Visión, 2003, pp. 127-128; Tomás Tadeu De Silva, Documentos de identidad. Una introducción a las teorías del currículum, Belo Horizonte, Auténtica Editorial, 1999, p. 
de 'no correspondencia' entre las dimensiones política e ideológica en torno a sexualidad y género en el sistema escolar: mientras que sus políticas no fueron consideradas prioritarias para la agenda ministerial durante toda la década, la ideología implicada tuvo una importancia central, llegando a polarizar, cada vez que el tema emergió en el debate público, el campo de disputa por su control. De hecho, sexualidad y género serían dimensiones axiales en la estructuración del campo de pugna educacional en los inicios de la transición, ya que en sus contornos las distintas fuerzas políticas e ideológicas jugarían su peso e inclinarían, al menos en parte, la gramática ideológica de la escuela de la década de 1990.

Desde el punto de vista político, en un contexto de retroceso del movimiento feminista y de mujeres ${ }^{10}$, el Ministerio de Educación (MINEDUC) incorporó asesores y mantuvo personas encargadas del tema, quienes trabajaron sin mayor atención pública y debieron coordinar muchas de sus iniciativas con el Servicio Nacional de la Mujer (SERNAM) y con el Ministerio de Salud (MINSAL) antes que con el propio MINEDUC. En una visión que se acoplaría a la más amplia presentada en el campo de la educación en particular, y de la política oficialista en general11, las funcionarias encargadas del tema asumieron una identidad 'experta' lo que supuso, por una parte, desconfiar de los conocimientos y bagajes que tenían las comunidades educativas, y por otra, tratar de articular las políticas a partir de un debate restringido a quienes estaban premunidos del saber científico.

Desde el punto de vista ideológico, dentro del campo oficialista se produjo una transformación en la interpretación del tema: si en los debates ocurridos a fines de la Dictadura el foco central estaba asociado a la misma categoría de género -lo que vinculaba la condición sexual con su construcción social-, a partir de principios de la década de 1990 primaría un enfoque basado en las problemáticas relacionadas a la dimensión biológica de la sexualidad. Las autoridades se vieron atrapadas en la contradicción que suponía, por una parte, otorgar valor público a los temas de sexualidad y género $\mathrm{y}$, por otra, $\mathrm{y}$ simultáneamente, afirmar de manera reiterada y firme que los principales educadores en la materia eran los padres y madres.

El campo de la oposición -acá asociada a la intelectualidad neoliberal, al conservadurismo católico y a los partidos políticos de derecha- rechazó los principios ideológicos levantados por el ministerio. Mientras que para los primeros el tratamiento de cualquier política central en género y sexualidad atentaba contra la libertad de enseñanza, según los segundos la educación sexual y de género debía estar basada explícitamente en la moral católica. Los terceros oscilaron entre ambas posiciones. De todas formas, el punto en común entre las distintas posiciones del campo opositor era el rol primordial de la familia en la educación sexual.

El desarrollo político global del proceso muestra que la debilidad ad intra

5; José Gimeno Sacristán, Saberes e incertidumbres sobre el curriculum, Madrid, Ediciones Morata, 2010; Antonio Viñao, "La historia de las disciplinas escolares", Historia de La Educación, 25, Universidad de Murcia, 2006, 243269.

10 Ver Ríos, op. cit.

11 Sebastián Neut y Marco González, “La noción de políticas públicas durante los gobiernos de Concertación. La reflexión de algunos intelectuales del periodo y consideraciones para una discusión histórica del problema", Cuadernos de Trabajo Social, 17, enero 2018, 103-124. 
ministerial y su desdén por convocar apoyo social, a la par con la fortaleza histórica de las fuerzas de oposición pro-Dictadura -ambas situaciones coadyuvadas por la común importancia otorgada a la libertad de enseñanza por sobre el valor público de la educación, se conjugaron para que, por una parte, las políticas educacionales en género y sexualidad fueran sumamente débiles en términos de su articulación política y pública y, peor aún, estuviesen casi totalmente a merced de los afanes del último sector aludido, el que hizo fracasar las más importantes de ellas.

Dicho lo anterior, el presente texto da cuenta en un inicio de los antecedentes que permiten comprender las opciones políticas e ideológicas tomadas por el primer ministerio transicional, para luego abordar tres de las más importantes políticas en el ámbito: la construcción de un documento programático de educación sexual junto a la propuesta del proyecto curricular de 1991-1992, el programa de Jornadas de Conversación Sobre Afectividad y Sexualidad (JOCAS) de 1996, y la construcción curricular de 1996-1998.

Para concretar la reconstrucción histórica hemos llevado a cabo una revisión de fuentes oficiales, documentos generados por el MINEDUC, publicaciones de centros de pensamiento y de prensa de la época, especialmente los diarios El Mercurio, La Nación y La Segunda. Asimismo, hemos examinado la revista oficial del Ministerio y la del Colegio de Profesores. Finalmente, hemos revisado en su completitud el inexplorado archivo de la Unidad de Currículum y Evaluación del Ministerio de Educación.

\section{Educación y género en los prolegómenos de la transición escolar}

El programa educacional de la Concertación fue incubado desde mediados de la década de 1980 dentro de un campo intelectual nucleado en torno a ONG's opositoras al régimen, fundamentalmente el Centro de Investigación y Desarrollo de la Educación (CIDE) y el Programa Interdisciplinario de Investigaciones en Educación (PIIE) ${ }^{12}$, que tenían destinadas líneas de investigación para estudiar las relaciones entre género y escuela. En el CIDE destacaba Josefina Rossetti y en el PIIE María de la Luz Silva, quien fue asesora de género y sexualidad durante el primer Ministerio de Educación de la recuperada democracia y mantuvo un vínculo con este durante todo el período estudiado.

En el contexto del plebiscito de 1988 una publicación oficial PIIE señaló que en la futura democracia había que evitar todo tipo de discriminación, entre ellas de género, y que había que apoyar a los padres para lograr "la superación de actitudes no democráticas que se desarrollan en sectores importantes de ellos. Es el caso del machismo y del autoritarismo"13. Con todo, fue solo en miras a la elección presidencial de 1989 que el tema adquirió un estatuto propio. En sendas publicaciones institucionales de CIDE y PIIE, tanto Rossetti como Silva, respectivamente, fueron las encargadas de redactar los capítulos

\footnotetext{
12 Desde una postura laudatoria ver María Inés Picazo, Las políticas escolares de la Concertación durante la transición democrática, Santiago de Chile, Ediciones UDP, 2013. Otra posición mantiene Sebastián Neut, "Prácticas y discurso intelectual en ONG's educacionales opositoras a la Dictadura chilena. Los casos del CIDE y PIIE", Revista Izquierdas, 42, octubre 2018, 198-223.

13 PIIE, Ruptura y construcción de consensos en la educación chilena. Santiago de Chile, PIIE, 1988, p. 34.
} 
destinados a analizar la situación escolar con perspectiva de género ${ }^{14}$, compartiendo una misma mirada y planteando similares políticas. Rossetti enfatizaba que la escuela tendía a reproducir los patrones socioculturales predominantes, con el consiguiente efecto discriminatorio hacia las mujeres, sobre todo en su vida adulta. Para ella, la escuela permitía "que los estudiantes mantengan intacta la noción de una división sexual de tareas de la jerarquía entre hombres y mujeres"15. Por su parte, Silva aducía que:

el problema del género cobra especial relevancia en la coyuntura en que se abre paso un proceso de democratización en el país. No será posible avanzar en esta tarea si el estereotipamiento [sic] de los roles asignados a los sexos no es abordado críticamente y, a la vez, se cuestionan las jerarquías de clase y de género' ${ }^{16}$.

Para enfrentar tal situación había que, según Rossetti, generar en primer lugar una "política de sensibilización" que condujese a la modificación de la cultura escolar, sobre todo la de los docentes: "planteamos ésta como la primera medida por cuanto consideramos decisivo el factor humano. Si un docente está sensibilizado puede hacer mucho, aun cuando no cuente con los currícula o los textos escolares más adecuados" 17. Junto con esto, Silva agregaba que había que "sensibilizar para que se reconozca y difunda la importancia de la temática de género por parte de maestros, alumnos, trabajadores de la educación, familias, comunidad y autoridades"18. Tales apreciaciones estaban en línea con la visión que sostenían las ONG's en términos más amplios respecto de la escuela. Para estas, el núcleo de los problemas en educación se encontraba no tanto en las políticas dadas "desde arriba" -es decir, desde el nivel central del Estado- sino que en la misma "cultura escolar", asociada centralmente a anticuadas, oprobiosas y autoritarias prácticas docentes. En síntesis, las autoras asociaban el problema a un conjunto de factores que se desarrollaban al interior de la escuela, los que terminaban por inducir a una depreciación de las mujeres tanto en su autoestima como en relación a otros factores, como la posición laboral19.

Con todo, tales ideas no lograron permear la sección destinada a la educación en el programa de gobierno de Aylwin -aunque el tema de la mujer ocupó un rol no despreciable, llegando a plantearse modificaciones al Código Civil y el establecimiento de

\footnotetext{
14 María de la Luz Silva, "Perspectiva de género en las políticas educacionales", PIIE, Educación y transición democrática. Propuestas de políticas educativas, Santiago de Chile, octubre de 1989; Josefina Rossetti, "Educación y subordinación de las mujeres", Eduardo García Huidobro (ed.), Escuela, calidad e igualdad. Los desafíos de educar en democracia, CIDE, 1989.

15 Rossetti, op. cit, p. 105.

16 Silva, op. cit, 105.

17 Rossetti, op. cit, p. 115.

18 Silva, op. cit, p. 106.

19 Opiniones similares plantearon en la institución "Concertación Nacional de Mujeres por la Democracia", creada en julio de 1989 y que intentaba incluir las demandas del movimiento feminista dentro de los contornos de los futuros partidos políticos oficialistas. Josefina Rossetti ocupó el cargo de secretaria ejecutiva, mientras que Silva lideró la comisión de educación. Ríos y Godoy, op. cit, p. 58. Los resultados de las comisiones en Sonia Montecinos y Josefina Rosseti, Tramas para un nuevo destino: Propuestas de la Concertación de Mujeres por la Democracia, Santiago, Concertación de Mujeres por la Democracia, 1990.
} 
un organismo de rango ministerial20-. Dichas ideas tampoco tuvieron cabida en los temas que, tras el triunfo del candidato concertacionista, se discutieron en los equipos formados para generar una agenda concreta para el primer Ministerio de Educación de la democracia a recuperar ${ }^{21}$. Menos fueron parte del diseño político del primer ministerio transicional ${ }^{22}$.

\section{Primeras medidas y el primer apronte: el debate por la sexualidad escolar en 1992}

Al ser contratada Silva en calidad de asesora de género y sexualidad, por primera vez en la historia educacional de Chile se incorporó la dimensión de género a la estructura interna del Ministerio ${ }^{23}$. Comentaba, a meses del recambio de régimen, que en la cartera existía un compromiso respecto del tema, "que se demuestra con la invitación a colaborar que me ha hecho el ministro Ricardo Lagos, quien con esto desea incorporar una visión distinta, desde la mujer y en su relación con los hombres e iniciar la modificación de esta condición de desigualdad, que tiene raíces profundas, por lo que se hace difícil avanzar" 24. Por otro lado, profundizaba en una poco promisoria visión respecto del mundo docente en torno al tema, al plantear que:

si existió alguna insuficiencia en las demandas del Colegio de Profesores en relación al tema de la mujer, que constituyen la mayoría del profesorado, es responsabilidad de las propias profesoras. El Ministerio no puede hacerse cargo de las insuficiencias en la participación de las profesoras en su gremio ${ }^{25}$.

20 Programa de Gobierno Concertación de Partidos por la Democracia, Sección “Incorporación plena de la mujer y protección de la familia", 1989, p. 7.

${ }_{21}$ Eso al menos se desprende de las comisiones que enumera Picazo. Picazo, 2013, op. cit., p. 259.

${ }^{22}$ Quienes conformaron el equipo que decidió la agenda para el MINEDUC entendieron que su principal rol era no formar obstáculo alguno para la consolidación de la democracia, lo que tenía como condición no irritar (en términos ideológicos) a los empoderados sectores prodictadura. En vistas de la configuración de un proceso que se pensaba gradual y acumulativo, decidieron establecer tres prioridades de políticas: el P900, el proyecto Mece básica y el estatuto docente.

23 Las primeras políticas de educación sexual incardinadas en el sistema escolar se desarrollaron en el período 1967-1973. Estas fueron interrumpidas por la Dictadura, la que reforzó una visión de la mujer cuyos roles e identidad debían afincarse en el ámbito privado y cuyos valores por antonomasia eran la abnegación y devoción en el contexto de una familia tradicional. Ver Arenas, op. cit., pp. 30-34; Andrea Zamora, “La mujer como sujeto de la violencia de género durante la dictadura militar chilena: apuntes para una reflexión", Nuevo Mundo Mundos Nuevos [en línea], 2008, y Verónica Valdivia Ortiz de Zárate “¿Las "Mamitas de Chile"? Las mujeres y el sexo bajo la dictadura pinochetista", Julio Pinto Vallejos (ed.), Mujeres: Historias chilenas del siglo XX, Santiago de Chile, LOM, 2010. Para el caso escolar ver Jorge Ochoa, "La sociedad vista desde los textos escolares”, CIDE, Santiago, 1983.

24 Informe final, Encuentro de la Concertación de Mujeres por la Democracia, Santiago, El Canelo de Nos, septiembre 1990, p. 58.

${ }^{25}$ Idem. La culpabilización de la actoría social de la mujer era más amplia. En un seminario planteaba que "resulta lamentable darse cuenta que, con la apertura del sistema político, quienes aparecen en el escenario público no son quienes habían estado todo el tiempo, es decir, las mujeres y los jóvenes. Quienes aparecen son los varones... A estas alturas habrá que preguntarse también ¿Hasta qué punto la responsabilidad por la baja participación política de las mujeres deba ser buscada en los 'otros' y cuánto en 'nosotras'?... El hecho es que frente a la discriminación existente, las mujeres no reaccionan con suficiente asertividad, exigiendo sus espacios de participación, instalándose en ellos desde su modo de ser mujer, imponiendo su propia y particular visión del 
Junto con ella, un conjunto de funcionarias fue prontamente vinculado al Programa de la Mujer, el que resultó dependiente del Departamento Extraescolar y Programas Formativos Complementarios de la División de Educación General, lo que evidencia la importancia secundaria otorgada al tema ${ }^{26}$.

Muy prontamente se produjeron roces entre el campo oficialista y el conservadurismo católico y la derecha neoliberal en torno a las características y alcances que la sexualidad y la afectividad debían tener en el contexto escolar. El mismo año de recambio del gobierno, este desistió de entregar unas cartillas de educación sexual en la V región, ya que la iniciativa "causó dificultades políticas y con la Iglesia católica, por lo que se resolvió quedara como iniciativa privada, dejando abierta la posibilidad de conversar acerca de su implementación" 27 . La advertencia política para el Ministerio fue clara, planteando Silva que era necesario generar un debate "de acuerdo a lo que se necesita y a lo que es posible"28. En 1991 se produjo otra situación semejante, cuando la parlamentaria de derecha María Angélica Cristi impugnó públicamente otra cartilla distribuida en Santiago 29 .

De cualquier manera, el primer gran 'ejercicio' político e ideológico en el que se puso en juego el poder de decisión sobre la agenda pública se produjo al año siguiente ${ }^{30}$. Coordinada por Silva, a principios de 1991 el Ministerio generó una "Comisión Consultiva de Educación Sexual", que en noviembre del mismo año evacuó el informe "Hacia una Política de Educación Sexual para el Mejoramiento de la Calidad de la Educación"31. La construcción del informe se produjo a partir de la concurrencia de un grupo reducido de funcionarios concertacionistas y 'expertos' en la materia, lo que iba en línea con la decisión del Ministerio de restringir el debate público para la construcción de políticas escolares, como manera de evitar - en sus consideraciones - la 'contaminación' de estas con intereses particularistas y muchas veces legos en las materias a discutir ${ }^{32}$. A pesar de esto, el grupo escogido sabía de la sensibilidad política y axiológica del tema, por lo que intentaron no herir -como se verá, infructuosamente- las susceptibilidades del catolicismo conservador y de la mayor parte de la derecha política. A propósito de tal cautela, la coordinadora

mundo", María de la Luz Silva, "Mujer y participación política”, En Participa, "La identidad femenina en situaciones de conflicto y poder", Editorial Andrés Bello, Santiago, 1992, pp. 84-85.

26 Guerrero, op. cit.

27 Informe final, op. cit., 1990, p. 58.

28 Idem.

${ }^{29}$ La Nación, "Matrícula para la educación sexual", Santiago, 15 de marzo, 1992, p. 8.

30 Antes, en 1990, pero fuera del rango de acción ministerial, se desarrolló un Encuentro Nacional Sobre Educación Sexual, el que fue organizado por el Programa de Apoyo y Extensión en Salud Materno Infantil (PAESMI), con el auspicio del Fondo de Población de Naciones Unidas (UNFPA), y que terminó con la "Declaración de Lo Barnechea" a ser entregada al ministro de educación. Hasta donde sabemos, este encuentro no aparece en la discusión ministerial posterior.

31 Además de la autoridad mencionada, estuvo compuesta por: Suzanne Aurelius, directora del Programa de apoyo y extensión en Salud Materno Infantil (PAESMI); Flavio Cortés, sociólogo del Instituto Nacional de la Juventud; Enrique Cueto, Director del Instituto Carlos Casanueva; Andrés Domínguez e Hilda Hernández, asociados al SERNAM; Rodrigo Hess, Presidente Comisión Nacional del SIDA; Bernardita Icaza, de CIDE; Tony Mifsud S.J., director de ILADES; Victoria Passache, psicóloga en la facultad de medicina de la Universidad de Chile; Rodrigo Vera, consultor UNESCO, y Benjamín Viel, de la Academia de Medicina del Instituto de Chile. 32 Neut, 2018, op. cit. 
expresaba que el ministerio no podía "definir cuáles deben ser los contenidos de la educación sexual. Necesita encontrar con las familias y la comunidad una base común en la que todos estén de acuerdo" ${ }^{33}$. En ese sentido señalaba que:

no hay acuerdo en la sociedad chilena sobre la definición de una conducta sexual responsable... por eso el Estado no puede pasar por sobre las familias para definir los valores que quieren transmitirles a sus hijos. El sistema educacional sólo interviene para ayudar, colaborar a la educación sexual de los hijos en todo lo que haya consenso. Por el momento hay acuerdo en que la sexualidad no es un tema secundario del que se pueda prescindir en la educación. Hay unanimidad para considerarlo una necesidad básica del aprendizaje ${ }^{34}$.

El problema era complejo bajo la luz de la interpretación aludida, ya que el Estado solo podría actuar en aquellas materias de educación sexual en que hubiese acuerdo. No obstante, ese acuerdo no existía en casi ninguna materia, excepto en la importancia de tratarlo. Al respecto, el informe intentó englobar las divergencias sociales que se producían en torno a los alcances de la sexualidad en una mirada común y nacional. El documento tenía como propósito:

identificar elementos básicos relacionados con la comprensión de la sexualidad humana que, a juicio de la Comisión son compartidos en nuestra sociedad... Tampoco se pretende establecer un concepto definitivo y único. Se pretende, tan sólo, esbozar criterios generales que permitan identificar lo común dentro de la diversidad ${ }^{35}$.

La apelación a la importancia primordial de la familia como educador en la generación de patrones de género y sexuales fue central. En el informe se aceptaba que el primer educador era la familia y que la libertad de enseñanza aseguraba la presencia de diferentes visiones en torno al tema. Al Estado cabría un rol subsidiario, que se traduciría en el apoyo y promoción de la participación de la comunidad en la reflexión y la implementación de iniciativas tendientes a tratar el tema, sin inmiscuirse en posición alguna respecto de la sexualidad optada por padres y comunidades.

El texto fundamentaba la importancia de establecer políticas educacionales en relación al tema a partir de la idea de que "una adecuada educación en sexualidad, al promover un mejor conocimiento de sí mismo, contribuye a desarrollar la aceptación de sí, facilita los sentimientos de autoestima y ejercicio de la responsabilidad, elementos que sirven de base para la vida afectiva y sexual posteriores" ${ }^{36}$. Es decir, la construcción de la sexualidad escolar se vinculaba centralmente a la preocupación biológica y afectiva por y para sí mismo-a. Complementariamente, los objetivos de la educación sexual se asociaban al desarrollo de la identidad sexual del estudiante, a la aceptación y amor hacia el otro y al reconocimiento crítico de los prejuicios en torno al tema.

33 La Nación, Santiago, 15 de marzo, 1992, op. cit., p.8.

34 Ibid, p. 9.

35 Ministerio de Educación, Hacia un Política de Educación Sexual para el Mejoramiento de la Calidad de la Educación, Santiago, 2001, p. 15.

36 Ibid, p. 16. 
De manera simultánea -y utilizando el mismo patrón de construcción políticadentro del ministerio otra Comisión se encontraba redactando una nueva propuesta curricular para todo el ciclo escolar ${ }^{37}$, la que estableció una estructura inédita en la historia curricular chilena al estipular Objetivos Fundamentales Transversales (OFT). Estos demandaban "acciones didácticas y educativas de parte de todas las instancias y agentes involucrados en el quehacer escolar" 38 y "poseen casi sin excepción un marcado sesgo ético-axiológico" 39 . Una de las categorías de OFT correspondió a "temáticas emergentes"40, entre las cuales se consideraba Afectividad y Sexualidad Humana.

Ambos informes fueron hechos públicos masivamente como adendas a una edición de la Revista Oficial del Ministerio en marzo de 1992. El tratamiento de esta temática -junto con otras como los Derechos Humanos -prontamente levantó la indignación de la oposición. La derecha neoliberal interpretó que el tratamiento de tales temas en los marcos dados por el ministerio resultaba lesivo a la libertad de enseñanza. Patricia Matte, por ejemplo, directora de programas sociales de Libertad y Desarrollo, planteaba respecto de las temáticas emergentes que existían "diversas posturas sujetas a discusión, y no aparece tan claramente un espacio grande a la familia". Consideraba que la única competencia del ministerio era la prescripción de la importancia de la educación sexual, señalando: "es relevante este tema. Solamente eso. Dejemos que cada establecimiento responda a qué le da relevancia y cómo se le da"41. Más drástica era la posición de Lucía Santa Cruz, parte de la misma institución, para quien siquiera tratar un mínimo curricular respecto del tema de educación sexual no resultaba adecuado porque era un tópico sobre el que no existía consenso a nivel nacional:

Más allá de la objeción a la idea misma de impartir educación sexual en forma grupal y de sustraer así esta tarea del ámbito de los padres -que constituyen el medio natural para ello -una vez más surge la obligación de preguntarse cuáles serán los criterios de moral sexual que el sistema educacional deberá asumir y a través de qué contenidos lo hará. ¿Se presentarán los contraceptivos como buenos o malos? ¿Se enseñará que la masturbación es parte del desarrollo normal de la sexualidad o 'un serio desorden moral', como afirma la Iglesia? ¿Se dirá que las relaciones prematrimoniales son buenas o malas? ¿Qué la homosexualidad es una anormalidad, o simplemente otra opción sexual más? ¿Qué el aborto es un derecho de la mujer sobre su cuerpo o un asesinato? ${ }^{42}$.

Al interior de la jerarquía de la Iglesia católica se produjo una situación compleja, ya que en su seno convivían diferentes tradiciones morales y políticas, cada una de las que evaluó la propuesta curricular y el informe de educación sexual de manera discordante.

${ }^{37}$ Cristian Cox, “Construcción política de reformas curriculares: el caso de Chile en los noventa”. Profesorado. 10, 2006, p. 22. María Inés Picazo, “La reforma del currículo escolar en Chile: entre tensiones creadoras y consenso necesario", Pensamiento Educativo, 40:1, 2007, 313-333. Un estudio histórico del proceso aludido en Sebastián Neut, "El conocimiento escolar en disputa en Chile: el caso del currículum fracasado de 1992", Currículo sem Fronteiras, v. 18, n. 2, maio/ago. 2018, 614-638.

38 Propuesta, 1992, op. cit., p. 6.

39 Idem.

40 Ibid., p. 7.

41 El Mercurio, "Partes Reiteraron Posición ante Informe Educacional”, Santiago, 31 de marzo, 1992, C8.

42 El Mercurio, “Objetivos Transversales. El Estado y los valores en Educación”, Santiago, 3 de mayo, 1992, E5. 
Aquellos desacuerdos escalaron de tal manera que incluso se sospechó de un quiebre interno, situación en la que la dimensión sexual de la educación jugó un rol central. Pese a que actores relevantes de la jerarquía eclesiástica aplaudieron públicamente las medidas tomadas ${ }^{43}$, pronto el ala conservadora hizo ver sus desavenencias. En abril el obispo de Rancagua Jorge Medina se mostraba escandalizado por el contenido del Informe, ya que no estaba fundamentado en la moral cristiana. Planteaba:

me causa mucha sorpresa que el documento no vincule en forma directa, constante y explícita, la sexualidad con el matrimonio y con la multiplicación del género humano. Esta laguna es muy seria, dándole un matiz de grave insuficiencia al tema de las relaciones sexuales prematrimoniales, que son abordadas solo con un criterio estadístico, o a los embarazos no deseados. ¿Qué pensar de una educación sexual que nada dice acerca de la nobleza del matrimonio, de su indisolubilidad, de la dignidad de la procreación, y que deja entender que las conductas sexuales se sitúan más en el campo de los cambios culturales que en el de una auténtica moralidad? ${ }^{44}$

El tema fue tratado en asamblea plenaria ordinaria de la Conferencia Episcopal, tras la cual los prelados emitieron una declaración en la que afirmaban que "ante versiones que hacen aparecer a la Conferencia Episcopal apoyando el documento de trabajo sobre educación sexual debemos manifestar que ésta no se ha pronunciado sobre el mencionado texto" ${ }^{\prime 4}$. A estas alturas en la opinión pública se ventilaba que existía un quiebre dentro de la jerarquía eclesial. De hecho, sus autoridades debieron en conferencia de prensa desmentir tales rumores y "tanto González como Caro manifestaron su confianza, motivada por la fe, en que los prelados alcanzarán un consenso y presentarán su propuesta al Ministerio de Educación" 46.

Finalmente, el episcopado entregó el informe de su posición oficial al ministerio en agosto. El documento evacuado tuvo un acápite específico destinado a comentar el informe de educación sexual, en que predominó claramente la visión conservadora. Su apertura resultó paradigmática: "la inclusión de la sexualidad entre los 'temas emergentes' no aparece como adecuada" 47 . Esto hacía referencia a que debía ser un tema central y no tangencial. Era planteado que, "comparando la propuesta ministerial con la doctrina y la concepción católica de la sexualidad humana, falta en aquella", entre otras, "un más explícito reconocimiento de la dimensión trascendental de la persona, cuyo fin es Dios";

43 Específicamente monseñor Camilo Vial, encargado de educación de la Conferencia Episcopal, y monseñor Faustino Huidobro, Vicario de la educación. El Mercurio, 26 de marzo, 1992, C9. También lo hizo el rector de la Universidad Católica de Temuco, Jorge Hourton. La Nación, “Catolicismo y educación sexual”, Santiago, 21 de abril, 1992, p. 12.

44 El Mercurio, “Mons. Medina Señala Falta De Fundamentación Moral En Educación Sexual”, Santiago, 7 de abril, 1992, C5.

45 El Mercurio, "Obispos Precisan que no se han Pronunciado Sobre Educación Sexual”, Santiago, 9 de mayo, 1992, p. C9.

46 El Mercurio, “El Episcopado niega división en iglesia” Santiago, 10 de julio, 1992, C1 y C2.

47 Revista Servicio, Aportes del comité permanente del episcopado de Chile a la propuesta del Ministerio de Educación sobre Objetivos fundamentales y contenidos mínimos de la enseñanza básica y media y al documento Hacia una política de educación sexual para el mejoramiento de la calidad de la educación en Chile, Santiago, agosto 1992, p.12. Negritas en el original. 
asimismo "un sentido más totalizante de la sexualidad, que la vincule a la realización plena de la persona, es decir, al amor como donación de sí y entrega al otro, y a la obertura a la vida al interior del compromiso matrimonial", destacando "la importancia de formar hábitos virtuosos, como el dominio de sí mismo, el esfuerzo, el sacrificio, la fidelidad, la castidad y la virginidad. No hay que desconocer que la continencia es la mejor garantía frente a muchos conflictos sociales de la sexualidad, como son el SIDA y el aborto" 48 .

Con la publicación del documento oficial, monseñor Carlos González daba por zanjado el tema y expresaba que "las discrepancias surgidas al interior del clero chileno fueron subsanadas en forma civilizada"49. El ministerio también intentaba dar por terminada la polémica, esta vez dando por perdido el proyecto de construcción curricular. Las temáticas que condujeron a tal situación fueron, protagónicamente derechos humanos, ecología y sexualidad.

\section{Los "intentos fallidos" (1993-1996): Política de Educación en Sexualidad y Jornadas Comunitarias de Afectividad y Sexualidad (JOCAS)}

El año 1993 marcó el inicio de una nueva etapa en la orientación de la política pública acerca de las temáticas relativas al género y la sexualidad. Esta fase tuvo como característica fundamental la institucionalización de la educación sexual, junto con la delimitación y transferencia, cada vez más evidente, de la temática de género, problematizada fuertemente desde fines de la Dictadura e inicios de la Transición, hacia la sexualidad adolescente. Destacaron en estos años dos iniciativas. La primera fue la llamada "Política de educación en sexualidad para el mejoramiento de la calidad" elaborada por el Comité Consultivo de 1991 y tomando como referencia el documento base de 1992 publicado a través del órgano oficial de la cartera. La segunda fue el establecimiento de las Jornadas Comunitarias de Afectividad y Sexualidad (JOCAS), una acción integrada de educación sexual en establecimientos educativos que tuvo una gran repercusión en el debate público. Ambas iniciativas pueden ser calificadas como "fallidas", debido, entre otras razones, a su insuficiente impacto, en el caso de la primera, y, en relación a la segunda, a la fuerte resistencia de algunos sectores conservadores con importante influencia política. Es necesario destacar que la propuesta de las JOCAS se planteaba como una instancia de diálogo para la comunidad escolar, lo que demuestra una preocupación por la dimensión cultural o subjetiva de la construcción identitaria adolescente. Sin embargo, esta permaneció circunscrita a la dimensión de la sexualidad, sin incorporar una problematización de los roles y estereotipos de género que se visualizaban en la discusión del período anterior. Esto tomando en cuenta el planteamiento programático e institucional de las JOCAS, sin desmerecer, naturalmente, la posibilidad de que estas temáticas fuesen intencionadas por sus participantes de manera situada.

Algunos fundamentos considerados para la elaboración de la política de 1993 fueron la creciente preocupación institucional, tanto educacional como de salud pública, y

48 Idem.

49 El Mercurio, Santiago, 19 de agosto, 1992, C5. 
el debate social y comunicacional respecto al embarazo adolescente y las infecciones de transmisión sexual (ITS, en particular el VIH) ${ }^{50}$. En 1992 se había publicado la circular 227 que buscaba asegurar la continuidad escolar de estudiantes embarazadas y madres dentro del sistema. En la misma línea, el SERNAM junto a UNICEF y el Centro de Medicina Reproductiva Adolescente (CEMERA) publicaron el mismo año un estudio sobre embarazo adolescente ${ }^{51}$. Un año antes, investigadores financiados por FONDECYT habían sacado a la luz resultados claves sobre un estudio exploratorio basado en una encuesta sobre riesgo de transmisión de VIH y conducta sexual en adolescentes. ${ }^{52}$

El tenor de la Política de Educación en Sexualidad fue principalmente preventivo respecto de ciertas conductas sexuales juveniles. Propuso crear comités de educación en sexualidad en los distintos niveles de enseñanza ${ }^{53}$ para, entre otras cosas, prevenir el embarazo adolescente y el aumento de ITS. Por otra parte, el documento fue enfático en destacar el rol secundario del Estado frente al papel de la familia, protagonista y responsable de la educación sexual ante el rol secundario de la escuela. Las orientaciones contenidas en dicha política alcanzaban el carácter de recomendaciones, permitiendo la discrecionalidad de sostenedores y establecimientos, a modo de garantizar la libertad de enseñanza. De esta manera, no se establecieron contenidos, sino que se explicitaron algunos criterios dejando un amplio margen de responsabilidad y autonomía para la elaboración de programas acordes a los diferentes proyectos educativos, dejando en manos de las mismas comunidades la búsqueda de los contenidos apropiados para abordar la temática. ${ }^{54}$

50 En distintos momentos del período 1990-1998 se registró, por parte de diversos actores educativos, una inquietud por abordar temáticas relativas a sexualidad. En particular, el MINEDUC transmitió en ocasiones su preocupación por el aumento del VIH y del SIDA entre la juventud. Asimismo, se expusieron algunas evidencias a partir de investigaciones que recogían testimonios de estudiantes sobre sus percepciones en torno a la educación sexual, revelando, de acuerdo a la publicación, resistencias, desconocimiento y "actitudes machistas" entre escolares. Reveduc, Revista de Educación, “Cuánto saben sobre sexo los jóvenes?”, n 180, Santiago de Chile, Ministerio de Educación, septiembre 1991; Ibid., “Que sea una niña tranquila...”, n²37, agosto 1996. Por su parte, el gremio docente, a través de la publicación oficial del Colegio de Profesores, se mantuvo ajeno a la discusión sobre educación sexual, al menos desde 1996, año del lanzamiento del primer número de la revista, hasta 1998. La Revista Docencia centró el foco de la discusión en los ideales de la educación, vinculándolos al desarrollo de la conciencia democrática, el respeto por los derechos humanos y la no discriminación de ningún tipo, sin dedicar artículos específicos a temáticas relativas a género o educación sexual.

51 Ramiro Molina (ed). Adolescente embarazada en Chile. Diagnóstico de la situación 1991, SERNAM, UNICEF, CEMERA, 1991.

52 J. Bernal, H. Bonacic, V. Edwards, R. Méndez, J. Guler. “Encuesta sobre conducta sexual de adolescentes. Proyecto FONDECYT", La Segunda, marzo 1992.

53 Documento de MINEDUC, “Mejoramiento de la calidad de educación (MECE)” En Jaime Fernández, JOCAS: La punta de un Iceberg, Santiago, Editorial PATRIS, 1996, p. 63.

54 Ministerio de Educación, Politica de Educación en Sexualidad. Para el Mejoramiento de la Calidad de la Educación, Santiago Chile, 1993. De acuerdo a José Olavarría y Rodrigo Molina, "tanto esta política como la Circular 227 no eran consideradas obligatorias; según sostenedores de establecimientos educacionales, contradecía la Ley Orgánica Constitucional de Educación (LOCE). De ahí la acción discrecional por la educación sexual y la mantención o incorporación de alumnas embarazadas y madres a sus establecimientos educacionales. Un caso de rechazo de matrícula terminó en los tribunales de justicia y finalmente llegó a la Comisión Interamericana de Derechos Humanos; fue fallado en la Comisión y el Estado de Chile conminado a modificar la ley (LOCE) para reconocer el derecho a la educación por sobre la libertad de enseñanza. Por primera vez la oposición dio su apoyo a una ley que modificaba la LOCE (Ley 19.688 de Protección a la Embarazada Adolescente, en agosto del 
Pese a la incorporación de la educación sexual en la agenda pública, la política de 1993 ha sido evaluada como poco exitosa por distintas investigaciones, considerando, entre los argumentos, la falta de obligatoriedad en su implementación ${ }^{55}$, el fracaso de la reducción de índices como embarazo adolescente y transmisión de ITS en la década siguiente $^{56}$, la resistencia de sectores conservadores y la escasa implementación en las escuelas, ya sea por falta de definiciones desde el ministerio o por oposición de actores educativos como sostenedores, familias y docentes. Lo anterior puede evidenciarse en un informe de evaluación de la política de 1993, realizado por la Comisión de Evaluación y Recomendaciones sobre Educación Sexual, formada por el MINEDUC el año 2004 y cuyo documento "Evaluación y recomendaciones sobre Educación Sexual" fue publicado el 2005. En dicho informe se explicita, entre otras cosas: que la Política de Educación Sexual de 1993 no asumió los fundamentos jurídicos de la Convención de los Derechos del Niño; que no se consideraron las particularidades de las familias chilenas y la necesidad de apoyo estatal en su tarea formativa; que los objetivos de la política eran muy amplios, lo que dificultaba su implementación; que al no contar con un plan definido la mayoría de las acciones emanadas de dicha política fueron aisladas; que los actores del sistema educativo afirmaron carecer de adecuada información y tener falta de apoyo del ministerio; que no se resguardó una conveniente instalación de la temática en la formación inicial docente; y que no se incluyeron otras temáticas tales como diversidad sexual, violencia intrafamiliar, abuso sexual infantil y discriminación. La Comisión señaló, además, la necesidad de "revisar y profundizar el principio de subsidiariedad" 57 , afirmando que

es claro que la actividad privada no es capaz por sí sola de establecer el orden de la sociedad. Atendiendo a la diversidad de situaciones familiares y de recursos de que dispone, así como déficit en las generaciones mayores en nuestro tema de análisis, se despliega un último contenido de la subsidiaridad en carácter de suplencia: crear condiciones y entregar a la escuela y la familia, herramientas necesarias para cumplir con su rol formativo en la educación sexual de niños y niñas, para que, a futuro, lleguen a realizar bien lo que, en principio, están llamados a cumplir como tarea propia [...] Una educación sexual adecuada considera a la familia como un actor preferente y relevante en el desarrollo de ésta. Ahora bien, asegurar una educación sexual de calidad, oportuna y veraz para todos, es un deber del Estado. Ello interpela a la familia, como primera formadora de sus hijos, y a la escuela en su corresponsabilidad ${ }^{58}$.

$\mathrm{Al}$ año siguiente, en el marco de la V Conferencia Internacional sobre Población y Desarrollo ${ }^{59}$ llevada a cabo bajo el auspicio de la ONU en El Cairo, el Estado chileno se

2000)". José Olavarría y Rodrigo Molina, "Embarazos en adolescentes, vulnerabilidades y políticas públicas", Polis, 11:31, Santiago de Chile, 411-433, abril 2012, p. 413.

55 Olavarría, 2012, op. cit.

56 José Olavarría, "La política de educación sexual del Ministerio de Educación de Chile. Consideraciones para una evaluación", Seminario Internacional Equidad de Género en las Reformas Educativas de América Latina, Hexagrama, 2005.

57 Idem.

58 MINEDUC, "Informe Evaluación y recomendaciones sobre educación sexual", pp. 33-34, 47-48, citado en Olavarría, 2005, op. cit.

59 Naciones Unidas, Informe de la Conferencia Internacional sobre la Población y el Desarrollo, El Cairo, Egipto. 1994. 
comprometió, como parte de los países firmantes del Programa de Acción a veinte años, a "proteger, garantizar y promover el ejercicio de derechos en materia de salud sexual y reproductiva de las y los jóvenes" 60 . Junto con lo anterior, el mismo año 1994, durante el gobierno de Frei, se creó un Comité Multisectorial de Educación Sexual y Prevención del Embarazo Adolescente en el que participaron representantes de distintos organismos públicos y el Fondo de Población de las Naciones Unidas (FNUAP). Este comité "tenía como objetivo principal esbozar las características que debiese considerar una primera estrategia que abordara la educación sexual en los establecimientos educativos, en democracia"61. Igualmente, en 1994, el SERNAM junto al MINSAL y otros presentaron el documento "Plan de Igualdad de oportunidades para las mujeres 1994-1999", que reflejaba el propósito de la primera institución por “integrar la equidad de género en las políticas públicas" 62 e incorporar a la agenda los acuerdos establecidos en El Cairo ${ }^{63}$.

En 1995, y considerando las iniciativas enumeradas anteriormente ${ }^{64}$, surgió el programa Jornadas de Conversación en Afectividad y Sexualidad (JOCAS). En el Plan de 1994 se habían definido objetivos específicos para la educación sexual, que luego serían abordados por las JOCAS, de acuerdo a Jaime Fernández ${ }^{65}$. La iniciativa de las Jornadas tenía una característica fundamental: por primera vez en el período se buscó implementar una política de sexualidad que incorporara a cuatro organismos diferentes: MINSAL, MINEDUC, Instituto Nacional de la Juventud (INJ) y SERNAM. El programa se inició con un piloto en cinco liceos del país. A la fecha de su finalización en el año 2000, estas jornadas se habían llevado a cabo en seiscientos liceos, "la mitad total del país"66.

Entre los motivos y causas de la creación e implementación de las JOCAS se erigían primero los diagnósticos sobre las problemáticas en la dimensión de la sexualidad vistas desde la salud. En específico, y al igual que en la política de 1993, el aumento de embarazo adolescente y la incidencia de VIH y SIDA fueron los principales catalizadores del programa. Junto con esto, y relacionado a lo anterior, se constataba "un déficit por parte de la familia para abordar estas temáticas" 67 , por lo que se buscaba contribuir desde la educación formal a la resolución de problemas tales como los "más de 40 mil adolescentes embarazadas todos los años" 68 y la promoción de una "sexualidad adolescente saludable

60 C. Dides, C. Benavente C, I. Sáez, L. Nicholls, “Educación Sexual en Chile. Implementación de la Ley 20.418." Boletín 4, UNFPA y Universidad Central de Chile, 2012.

61 Programa de Naciones Unidas para el Desarrollo (PNUD), Informe de Desarrollo Humano. Género: los desafíos de la igualdad. Santiago de Chile, 2010, p. 194.

62 SERNAM, Plan de Igualdad de oportunidades entre mujeres y hombres 2000-2010. Evaluación primera fase, Santiago de Chile, 2005, pp. 20-21.

63 Fernández, 1996, op. cit., p. 64.

64 Ibid., pp. 64-67.

65 Los objetivos señalados eran: “Objetivo 6.6: asegurar el derecho a una sexualidad libre de riesgos para la salud física y mental de las mujeres [...] Objetivo 6.7: asegurar el ejercicio de los derechos reproductivos y el acceso a la libre decisión sobre el número y espaciamiento de los hijos [...] Acción 6.8.1: promover la incorporación en los currículos de los últimos años de enseñanza básica y en la enseñanza media contenidos sobre sexualidad y reproducción e información científica sobre prevención de embarazos no deseados". Ibid, pp. 65-66.

66 PNUD, op. cit., p. 194.

67 Arenas, 2015, op. cit., p. 92.

68 La Segunda, Santiago de Chile, martes 10 de septiembre, 1996. 
y responsable en el nivel local" 69 .

La gran novedad de las JOCAS era su carácter participativo, fomentando el diálogo al interior de las comunidades escolares ${ }^{70}$. En el informe de evaluación de las JOCAS elaborado en 1997 por la coordinación interministerial (SERNAM, MINSAL, MINEDUC, INJ), se subrayaba la experiencia de autonomía y autogestión como un elemento puesto en relevancia por sus participantes ${ }^{71}$. De este modo, se destacaban las JOCAS como una "política de advocacy", es decir, como convocatorias a conversar"2 que, en muchos sentidos, rompieron tabúes y demostraron tener limitaciones y fortalezas. En ese sentido, se enfatizaba en su evaluación uno de los principales desafíos de las Jornadas: su adaptación institucional, puesto que "las JOCAS significan cambios en la matriz básica de la organización escolar, y no es fácil ni segura su capacidad de absorción y de proyección institucional. Las JOCAS son un 'movimiento' que, a su paso, remueve un orden y no termina por imponer un ajuste armónico [...] Las JOCAS presionan por un proyecto educativo -lo que ya es bastante- que, además, desarrolle sistemáticamente una línea de educación sexual.73.

Una de las finalidades de las jornadas era que los y las jóvenes desarrollaran "competencias para la vida, para asumir responsabilidades, para la participación social, para establecer vínculos afectivos y reproductivos responsables y satisfactorios, para establecer relaciones de confianza, para la autoestima y para el amor y la solidaridad en todas sus expresiones sociales"74, sin dejar fuera todos los y las agentes que participaban del proceso educativo. Entre estos últimos se incluían docentes y, especialmente, padres y madres, "reconociendo su responsabilidad en la materia" 75.

Las JOCAS se realizaban en liceos previa consulta a los distintos estamentos escolares, consulta convocada por el equipo directivo y los centros de padres. De esta forma, una de las premisas era que, gestionar dichas jornadas implicaba "generar las condiciones al interior del establecimiento para que se pueda realizar el evento"76. El

69 Informe del Subsecretario de Salud Ord. 4C/ N 1936 el 8 de abril de 1996; En Fernández, 1996, op. cit., p. 68. 70 Respecto de la metodología, las JOCAS consistían en "tres talleres de discusión realizados por un grupo de profesores seleccionados por cada establecimiento, profesionales capacitados por el Ministerio de Educación. En el primer taller se reunía a grupos de alumnos, padres y profesores a conversar informalmente sobre relaciones amorosas y sexualidad; luego, las inquietudes que surgían se resumían en preguntas. Durante el segundo taller, personal técnico externo, conformado por profesionales de la salud y de las ciencias sociales, respondía las preguntas entregadas a los estudiantes y sus familias. En el tercer taller los grupos originales se reunían nuevamente a conversar para levantar soluciones posibles a una problemática sexual específica. La experiencia se clausuraba con alguna demostración artística creada por los participantes... [esta] cumplía un doble objetivo: que los jóvenes se apropiaran de la reflexión generada en las jornadas en códigos más cercanos a la cultura juvenil (el arte), y "quitar las vendas" de los adultos (docentes y padres) al tener la oportunidad de conocer las concepciones reales de los jóvenes respecto de la sexualidad." PNUD, op. cit., pp. 194-195.

71 Manuel Canales, Gilda Aceituno, Germán Morales, Irma Palma y Juan Jiménez, Evaluación Jornadas de Conversación sobre afectividad y sexualidad, Santiago de Chile, Coordinación Interministerial SERNAM-MINSALMINEDUC-INJ, 1997, pp. 5-7.

72 Ibid., p. 15.

73 Ibid., pp. 48 y 53.

74 Paola Abatte, Paula Arriagada y Germán González, Texto guía para la autogestión de Jornadas de Conversación sobre Afectividad y Sexualidad, 1999, pp. 17-18.

75 Idem.

76 Ibid., p. 43. 
documento orientador explicita repetidamente la responsabilidad protagónica de las familias en la educación sexual, enfatizando el carácter coadyuvante del Estado (representado por la institucionalidad ministerial y el programa de las jornadas) en la tarea formativa de las familias ${ }^{77}$.

La implementación de las JOCAS fue ampliamente resistida por sectores conservadores, resonando en la prensa y en distintos actores de la época, especialmente la Iglesia católica, que reaccionó ante lo que consideraba una "entrega de contenidos sin un marco valórico"78. El PNUD recogió en 2010 parte de las críticas al programa implementado entre 1996 y 2000, entre las que destacan el reportaje de Pilar Molina “La nueva educación sexual del Estado. Directo al grano" que mostraba una fotografía de dos estudiantes con preservativos entre sus $\operatorname{manos}^{79}$. Esto encendió las alarmas de actores representantes del catolicismo y el conservadurismo como el Obispo Medina, Sergio Diez y Hernán Larraín. De acuerdo a los testimonios recabados en el informe del PNUD, el reportaje de Molina "fue un punto de inflexión a partir del cual se inició un proceso de declinación, conversión, debilitamiento y finalmente extinción de las JOCAS" 80.

A partir de septiembre de 1996 los medios de comunicación dieron espacio para las críticas favorables y desfavorables hacia las JOCAS, apoyándose incluso en profesionales como siquiatras y sicólogos de la Universidad de Chile y Católica81, junto con algunas encuestas.

Desde los sectores conservadores ligados al catolicismo, destacó la petición de la Comisión Permanente del Episcopado de retirar el programa de educación sexual, anunciando que, además, se prohibiría en los colegios católicos ${ }^{82}$. El Comité Permanente de la Conferencia Episcopal publicó el 10 de septiembre de 1996 un documento que abordaba las JOCAS señalando, entre otras cosas, que no consideraban el programa adecuado ni propiamente coherente con lo que consideraban educación sexual. En ese sentido, afirmaban que en las Jornadas se transmitía educación técnica sin vinculación con las dimensiones de desarrollo personal, alejándose del verdadero sentido de la educación sexual "para que pueda expresar su vinculación de amor con el otro sexo y llegar a formar una pareja estable en el matrimonio" 83 . Asimismo, argumentan a partir de "investigaciones realizada en Chile, con la más rigurosa metodología [...] [que señalan] que, entre los alumnos egresados de educación media, el $90 \%$ conoce todas las técnicas de control de la actividad sexual". De esta forma, enfocar la educación sexual para evitar "el problema del SIDA y del embarazo precoz" no sería el camino adecuado a su criterio ${ }^{84}$.

En la misma línea, se realizó un Seminario convocado por el rector de la Universidad Católica titulado “La formación de la sexualidad humana. Misión de padres,

77 Ibid.

78 Leo Arenas, Jennifer Durán, Claudia Dides, Constanza Fernández, Primer informe Salud Sexual y Reproductiva y Derechos Humanos en Chile, p. 18.

79 PNUD, op. cit., p. 195.

80 Idem.

81 La Segunda, Santiago, 13 de septiembre, 1996, p. 32

82 Ibid., 10 de septiembre, 1996, p. 14.

83 Comité Permanente de la Conferencia Episcopal, Acerca de la Educación Sexual, 10 de septiembre 1996. 84 Idem. 
educadores y jóvenes" 85 , respondiendo a lo que consideraban una "corrupción profunda sobre el sentido de la persona humana, del hombre y la mujer, que comprende una distorsión del sentido de la sexualidad"86. El directivo de la Universidad Católica, Juan de Dios Vial, quien afirmó no conocer el plan como para pronunciarse definitivamente, adhirió no obstante a las críticas, agregando que el material de trabajo era "francamente pornográfico" 87 .

Desde el ámbito de la oposición política asociada a los sectores de derecha, desde el mismo mes de septiembre de 1996 abundaron las críticas al programa y a las personas involucradas, acusando, entre otras cosas, que se promovía la masturbación, el aborto, el uso de condón y píldoras en detrimento de los métodos anticonceptivos naturales, y condenando a los municipios que implementaron las Jornadas. Sergio Diez, presidente del Senado en ese entonces, las consideraba transgresoras de la Constitución arguyendo que la Carta Fundamental establecía la familia como primera responsable de la educación de sus hijos/as. En consecuencia, solicitaría informaciones de los organismos y personas involucradas ${ }^{88}$. Renovación Nacional, por su parte, propuso el 15 de septiembre otros planes de educación sexual, esperando que el ya puesto en marcha fuera cancelado o reemplazado. En su propuesta, la columna vertebral era que los datos arrojados por las estadísticas hasta ese momento "se solucionan fortaleciendo los valores de la familia" 89.

En cuanto a organizaciones gremiales y civiles, destacó el "Movimiento Nacional por la Familia" que afirmaba, en base a una encuesta que llevaron a cabo, que "al rededor del $80 \%$ de los santiaguinos estima que la educación sexual es responsabilidad de los padres" 90 , y que la mayoría de las familias prefería decidir sobre la educación sexual de sus hijos e hijas. Junto con esto, abogaban por la libertad de elección y transmisión de valores siendo el núcleo familiar "la principal institución educadora y transmisora de valores"91, la cual no debía ser coartada o limitada. En la vereda opuesta, el Colegio de Profesores ofrecía un balance positivo de las JOCAS ${ }^{92}$.

Desde el oficialismo, el ministro de Educación reconocía que las Jornadas tenían falencias, pero que serían abordadas considerando "el apoyo de todos los sectores, incluida la Iglesia, con el objeto de mejorar la forma en que se está entregando la información en los establecimientos"93. Buscando ofrecer concesiones hacia la institución eclesiástica, enfatizaba que se estaban "solicitando los programas y proyectos de la Iglesia en materia de educación sexual, para que se puedan poner a disposición de los colegios municipales, porque ellos pueden estar más adelantados y ofrecer alternativas" 94 . Mientras tanto, los ministerios involucrados en la elaboración de las JOCAS se respaldaban desde diferentes

85 La Segunda, Santiago, 3 de septiembre, 1996, p. 15.

86 La Segunda, Santiago, 3 de septiembre, 1996, p. 15.

87 La Segunda, Santiago, lunes 3 de septiembre, 1996, p. 15.

88 El Mercurio, Septiembre - Octubre, Santiago, 1996; La Nación, Santiago, 9 de septiembre, 1996, p. 14; La Segunda, Santiago, 10 de septiembre, 1996, p. 14.

89 El Mercurio, Santiago, 15 de septiembre, 1996, C3.

90 La Segunda, Santiago, 2 de octubre, 1996, p. 15.

91 El Mercurio, Santiago, jueves 3 de octubre, 1996.

92 La Segunda, Santiago, 13 de septiembre, 1996, p. 35.

93 La Segunda, op. cit., 16 de septiembre, p. 13.

94 Idem. 
aristas: estadísticas del aumento de enfermedades venéreas, embarazo adolescente; movimientos feministas presentes de manera más transversal, e incluso cifras sobre el apoyo que ofrecían las familias a la educación sexual ${ }^{95}$. Así, desde el MINSAL respondían con un llamado a terminar la polémica, ya que acontecían otros eventos más urgentes y críticos que abordar ${ }^{96}$.

Reforzando esta argumentación, el subsecretario de Educación reiteraba que no se pretendía en ningún caso reemplazar a la familia ${ }^{97} \mathrm{ni}$

se ha impuesto la idea de promiscuidad o libertinaje sexual, como plantean sectores de la Iglesia Católica. Por el contrario, se escuchó a los jóvenes para determinar que dudas tienen en temas sexuales para, sobre esa base, con el apoyo de la familia, el colegio, la iglesia y el estado, elaborar planes efectivos para evitar problemas como el sida y el embarazo adolescente ${ }^{98}$.

La primera semana de octubre de 1996 diputados de oposición presentaron ante la Cámara un proyecto de acuerdo para la suspensión de aplicación de las JOCAS, el cual fue denegado por 47 votos contra $35^{99}$. No obstante, "las presiones surtieron efecto" y las JOCAS sufrieron algunas modificaciones, como la eliminación de las expresiones artísticas "por considerarse demasiado controvertidas"100. Asimismo, el libro "Jocas: la punta del iceberg" del sacerdote Jaime Fernández argumentó en contra del rol del personal de salud en las Jornadas, considerado, a su juicio, excesivo, reduciendo a su parecer una labor que debía ser pedagógica y ética a la esfera de la ciencia y la medicina ${ }^{101}$.

Estas y otras presiones contribuyeron al decaimiento de las JOCAS en distintos ámbitos. Primero, el MINEDUC asumió el control y financiamiento del programa ${ }^{102}$. Luego, en 1998, la Conferencia Episcopal aprobó el programa, que había experimentado cambios para su legitimación en el organismo eclesiástico. Por último, el presupuesto de las JOCAS fue reducido, mezclándose en ocasiones las temáticas de sexualidad con las de prevención de drogas. Las Jornadas dejaron de ser prioridad para las autoridades, disminuyendo paulatinamente ${ }^{103}$.

Tanto el Plan de sexualidad de 1993 como las JOCAS fueron intentos de posicionamiento de la educación sexual en la agenda pública, ya constreñida por una visión depurada de género y sexualidad desde los años previos, fuertemente limitada por el carácter preferencial de la libertad de enseñanza desde los establecimientos y las familias y, con todo, enérgicamente resistida estas últimas en su implementación. Las JOCAS fueron una

95 La Nación, “Un 66,5\% de acuerdo en que comience entre los 5 y 9 años la educación sexual y que no se omita ningún tema", Santiago, 27 de septiembre, 1996.

96 La Segunda, Santiago, 10 de septiembre, 1996, p. 15.

97 Ibid., p. 33.

98 María de la Luz Silva, coordinadora de las JOCAS. El Mercurio, Santiago, 15 de septiembre, 1996, D10.

99 Cámara de Diputados, Sesión 1ra, martes 1 de octubre de 1996, p. 27.

100 PNUD, op. cit., p. 196. Ver Canales, op. cit., pp. 59-63.

101 Idem. Ver Fernández, op. cit.

102 Esto pese a que el informe de evaluación había señalado como fortaleza el carácter intersectorial de las JOCAS, enfatizando que estas requerían de "un programa de educación sexual permanente en los colegios, y de atención y consejería equivalente en los consultorios". Canales, op. cit., p. 58.

103 Ibid., pp. 196-197. 
instancia inédita de diálogo sobre sexualidad, diálogo que permeó el debate público alcanzando un alto grado de controversialidad.

\section{Construcción de currículum o de cómo sexo y género terminaron por (casi) no tener cabida en el conocimiento escolar (1995-1998)}

Tal como ilustró el infructuoso proceso de construcción curricular de 1992, el currículum resultó ser el más sensible "territorio en disputa"104 dentro de las políticas escolares de la década de 1990. De hecho, este vino a ser prescrito a remolque de varias de otras políticas, posibilitado solo una vez que las fuerzas políticas del oficialismo y de la oposición de derecha habían allanado el camino para generar un "consenso en educación" 105 .

Cristian Cox -encargado de la construcción curricular de educación media- ha planteado que una de las 'lecciones' que legó el embarazoso proceso descrito fue que los OFT no serían tratados como temas emergentes sino como comportamientos personales susceptibles de evaluarse ${ }^{106}$. Con todo, y tal como esperamos demostrar, el tenor de la inclusión del tema de la sexualidad fue muy menor, tuvo alto nivel declarativo e incluso llevó al predominio de una visión conservadora, mientras que el del género propiamente tal, ni siquiera tuvo cabida.

El marco curricular de educación básica fue realizado durante 1995 sin mayores consultas públicas por parte de equipos técnicos y expertos ${ }^{107}$. Entre los OFT vinculados con la persona y su entorno hubo dos que incluyeron la dimensión sexual. El primero planteaba que el estudiante debía "comprender y apreciar la importancia que tienen las dimensiones afectivas y espirituales y los principios y normas éticas y sociales para un sano y equilibrado desarrollo sexual personal". A diferencia de la propuesta de inicios de década, en este caso la sexualidad -relativa exclusivamente a la persona- era vinculada al afecto y al espíritu a partir de ideales éticos y no de realidades sociales contextuales. El segundo lograba llenar de sentido y contenido tal ideal, al plantear que -ahora a nivel de socialización- se debía "apreciar la importancia social, afectiva y espiritual de la familia y de la institucionalidad matrimonial" 108 .

El proceso de construcción del currículum de educación media -desarrollado entre

104 Miguel Arroyo Currículo, Território em Disputa, Petrópolis, Editora Vozes Ltda, 2013.

105 La bibliografía y evidencia histórica indican que el "consenso en educación" solo se logró tras la convocatoria del gobierno de una Comisión Nacional para la Modernización de la Educación, que incorporó a una amplia gama de representantes de los diferentes interesados en el tema, que sesionó en 1994 y que evacuó el informe "Los desafíos de la educación chilena frente al siglo XXI". A partir de tal instancia, a principios de 1995 los diferentes partidos con representación parlamentaria firmaron un "acuerdo marco" para actuar en educación. Con todo, el Colegio de Profesores impugnó esta última iniciativa.

106 Cristian Cox, "Las políticas educacionales de Chile en las últimas dos décadas del siglo XX”, En Cristian Cox (ed.), Políticas educacionales en el cambio de siglo. La reforma del sistema escolar de Chile, Santiago de Chile, Editorial Universitaria, 2003, p. 7.

107 Cristian Cox, 2007, op. Cit, pp. 10-11.

108 Decreto 40. OFT relativos a la formación ética planteaba que el estudiante debía "reconocer, respetar y defender la igualdad de derechos esenciales de todas las personas, sin distinción de sexo, edad, condición física, etnia, religión o situación económica", mientras que 
1996 y 1998- fue más complejo en términos de su socialización y mediación por parte de la sociedad civil. A partir de la acción original de grupos expertos y de académicos por área, la propuesta curricular fue sometida a diferentes procesos de consulta, cuyos resultados, en todo caso, fueron procesados y discriminados por los primeros. Con todo, en lo que respecta a los temas planteados, casi no hubo aportes y/o reparos por parte de instituciones $\mathrm{y}$, los pocos que existieron, mayormente no considerados.

$\mathrm{Si}$ bien en un inicio sexualidad ${ }^{109}$ y género ${ }^{110}$ estaban contemplados como dimensiones a ser tratadas de manera diferenciada dentro de los borradores desarrollados por los encargados de construcción ad intra, tal fórmula desapareció prontamente del horizonte de la construcción curricular, y, mientras que el segundo no tuvo cabida, el primero fue enmarcado genéricamente a los OFT. Al respecto, la versión curricular destinada a ser socializada entre mayo y agosto de 1997, incorporó los siguientes: "comprender y apreciar la importancia que tiene la sexualidad para un sano desarrollo sexual personal" y, al igual que para básica, "apreciar la importancia social, afectiva y espiritual de la familia y de la institucionalidad matrimonial"111.

A diferencia de la situación anterior, resulta interesante constatar que -salvo el SERNAM y el Programa de la Mujer del MINEDUC- ninguna otra institución hizo reparos al tratamiento las dimensiones aludidas, incluida la Conferencia Episcopal112, mientras que a nivel individual solo lo hizo una persona. Al respecto, tras los procesos de consulta fue aceptada la propuesta del abogado Ricardo Gómez Blanco113, "referido al objetivo de la educación sexual, [en que] se sugiere agregar la dimensión afectiva, espiritual, ética y social para un sano desarrollo sexual"114, tal como quedó consignado en la versión final.

El SERNAM fue la única institución que evacuó un informe ${ }^{115}$, el que resultó muy crítico de la propuesta. Respecto del género, adujo la "ausencia de objetivo(s) transversal(es) que favorezca explícitamente el desarrollo de actitudes y relaciones equitativas entre hombres y mujeres" y la "ausencia, a nivel del diagnóstico que fundamenta la formulación de un nuevo currículum, de un análisis de los cambios que se han producido en las demandas que la sociedad hace en la actualidad a las mujeres y los consiguientes cambios en sus necesidades educativas". A su vez, respecto de la sexualidad, planteó que "el documento no da cuenta de una concepción sobre afectividad y sexualidad

109 En documento 1300 del Catálogo de la Unidad de Currículum y Evaluación (UCE), fechado el 26 de agosto 1996, el encargado de la construcción de OFT, Abraham Magendzo, plantea como tema a ser trabajado el de la educación sexual.

110 En documento 1342 del catálogo UCE, fechado el 15 de junio de 1996, el equipo de consultores propuso la generación de "Nuevos Ámbitos Curriculares", entre los que se encontraba “Temas de género".

111 Libro azul, P. 46.

112 Documento 1445 del catálogo UCE.

113 En el documento el jurista es denominado "consejero". A la sazón era el representante de la Corte Suprema en el Consejo Superior de Educación, organismo que debía aprobar la propuesta curricular. Gómez Blanco se hizo conocido durante la Dictadura por ser el autor del llamado "formulario blanco", una hoja tipo con espacios en blanco para poner los nombres de las personas por las que se solicitaba recursos de amparo y de protección, los que eran rechazados.

114 Documento 1342 del catálogo UCE.

115 Documento 1831 del catálogo UCE, con fecha 30 de julio de 1997, denominado “Comentarios a Documento Objetivos Fundamentales y Contenidos Mínimos". 
que conduzca a un desarrollo integral de los y las jóvenes"116, acusando, por otra parte, un "sesgo biológico" en el tratamiento del tema en las áreas científicas. Para subsanar algunas de estas cuestiones, proponía, entre muchos otros cambios, incorporar en la sección que fundamentaba el marco curricular lo siguiente:

una debilidad especial que ha caracterizado la E.M. y que se refiere no sólo a lo curricular, es la invisibilización de la mujer y lo femenino en el lenguaje, los textos de estudio, los programas, entre otros. En un espacio de socialización tan determinante como es el escolar, es necesario revertir esta ausencia, que no guarda relación hoy, con los cambios que está teniendo la participación social de la mujer. Cobra especial relevancia tener presente la existencia de estereotipos de roles sexuales que asignan espacios de desempeño específicos para hombres y mujeres, limitando las posibilidades de desarrollo más integral para unos y para otras. El desempeño de las diversas asignaturas, el acercamiento al conocimiento, los futuros estudios o desempeños laborales, están marcados por una jerarquía de preeminencia masculina que dificultan las posibilidades de desarrollo de las niñas ${ }^{117}$.

Tal adición no fue incluida. Lo mismo sucedió con la solicitud de modificar el OFT que aludía relacionado a la familia y al matrimonio, al proponer "apreciar la importancia social, afectiva y espiritual de la familia, del compartir roles familiares y su proyección en el conglomerado social en su conjunto, así como de la institucionalidad matrimonial y junto con ello estimular la práctica de relaciones democráticas al interior de la pareja"118.

Sin embargo, logró incluir el siguiente: "apreciar la importancia de desarrollar relaciones entre hombres y mujeres que potencien la participación equitativa de estos/as en la vida económica, familiar, social, política y cultural"119, aunque en la versión final se eliminó la dimensión política ${ }^{120}$. Los cambios propuestos también refirieron a diferentes asignaturas, aunque sin resultados favorables ${ }^{121}$.

En síntesis, mientras que la dimensión del género no tuvo cabida en el marco mínimo curricular, la sexualidad la tuvo, pero de manera muy acotada, genérica y tendiente a enfatizar una visión conservadora. Ello, a pesar de los severos reparos, no considerados, que levantó el SERNAM. Acaso por ello mismo, en esta ocasión no hubo

116 Documento 1831 del catálogo UCE, con fecha 30 de julio de 1997, p. 1.

117 SERNAM, op. cit., p. 2.

118 SERNAM, op. cit., p. 3.

119 Ibid, p. 3.

120 MINEDUC, op. cit., p. 21. En la dimensión de crecimiento y autoafirmación personal se sugirió sin éxito incluir el siguiente párrafo: "la socialización diferente de niños y niñas ha fortalecido entre ellos y ellas capacidades distintas. El sistema escolar procurará tenerlo en cuenta para conseguir aprendizajes significativos, de modo que la educación actúe como elemento potenciador de ambos grupos". Mismo resultado tuvo la petición de "promover el rechazo por cualquier forma de violencia física, psicológica y/o sexual contra otra persona".

121 Por ejemplo, en Lenguaje y Comunicación se solicitó adicionar literatura de autoras y el análisis de medios de comunicación en cuanto reproductores de estereotipos, lo que no fue incorporado. En Matemáticas fueron rechazadas las propuestas de incorporar el aporte de algunas mujeres a la disciplina. En Historia y Ciencias Sociales se proponía añadir el contenido "El cuestionamiento a los roles sexuales tradicionales; la mujer como un actor social presente pero no reconocido; el replanteamiento de lo femenino y lo masculino en la construcción de una sociedad en cambio", lo que no sucedió. 
ningún revuelo público.

\section{Conclusiones}

El fenómeno histórico descrito tiene una línea temporal que torna desde el amanecer hacia el ocaso: desde una primera fase en que los temas de género y sexualidad estaban imbricados en las luchas por su inclusión en el sistema escolar formal, se pasó a la medianía del día en que el debate se centró en incorporar -aunque tímidamente- políticas de educación sexual, para luego ceder paso al anochecer, en el que el género resultó totalmente marginado y despreciado, mientras que la sexualidad menospreciada.

Como telón de fondo se recorta un paisaje en el que las políticas públicas de los gobiernos de la transición entendían "la equidad entre mujeres y hombres... sólo en términos de paridad, comparando tasas por sexo en torno a distintos indicadores dependiendo de la problemática que se trate, entendiendo que la equidad se lograría cuando estas tasas se igualen"122. Sin embargo, no existió un cuestionamiento de las razones que llevaban a tal disparidad, a los mecanismos culturales y sociales en que se reproducían ni, en definitiva, a lo que Nancy Fraser (1997) llama la "socialización de género" 123 .

Lo cierto es que en la oclusión de los dilemas y disputas del género expuestos no solo se advierte un desconocimiento, ignorancia o debilidad de manejo en la agenda pública por parte del oficialismo. El sexo y las emociones, sobre todo juvenil, se alumbró como un mismo mecanismo de despolitización del género, en particular, y de la juventud, en general. Había que performar un adolescente y joven diferente del 'ochentero', combativo, politizado e interesado por el debate público. Por el contrario, el 'noventero' debía ser un ser sexual y emocional conocedor del sí mismo y desconectado de los vínculos de lo social del género y de la política. O, como planteaba en 1991 Enrique Correa, ministro secretario general del gobierno, "no creo que la principal preocupación de los jóvenes hoy sea la temática política -tanto o más importante son la música, los temas de la ecología, las relaciones afectivas-; por lo tanto, hay que generar incentivos para que ellos se conviertan en grandes temas de la sociedad"124.

Por otra parte, la poca atención a la política mostrada por el ministerio no era exclusiva de este $y$, de hecho, salvo la Iglesia católica y la derecha neoliberal, la sociedad civil tampoco mostró mucho interés en el tema. Por de pronto, el Congreso Nacional de Profesores realizado en 1997 es una instancia que permite evaluar las consideraciones docentes respecto del género en la década. De acuerdo al documento emanado de dicho congreso, existía una preocupación general por la promoción de una educación integral, crítica y respetuosa de la diversidad, aunque no se hacen lecturas específicas acerca de la

\footnotetext{
122 Elizabeth Guerrero, Transversalización de la perspectiva de género en Chile: en la búsqueda de la equidad, Ponencia presentada en el X Congreso del Centro Latinoamericano de Administración para el Desarrollo, Santiago de Chile, 2005, p. 2.

${ }^{123}$ Fraser, Nancy, Iustitia Interrupta. Reflexiones críticas desde la posición 'postsocialista', Siglo de Hombres Editores, Universidad de Los Andes, Colombia, 1997, citada en Guerrero, op. Cit.

124 Enrique Correa, "Sólo la verdad nos dará la tranquilidad que necesitamos”, Análisis, del 7 al 13 de enero de 1991, p. 22.
} 
educación y su rol en la reproducción de las diferencias de género, o de la responsabilidad profesional que atañe a los docentes en la superación de esa desigualdad. Las principales propuestas que apuntan a grupos calificados como "postergados" del ámbito educativo están dirigidas a "la enseñanza de adultos y jóvenes en situación irregular", tales como "adolescentes embarazadas, jóvenes con problemas de adicción, de alto riesgo social y alumnos con necesidades educativas especiales". En cuanto al rol de la familia, se destaca la necesidad de fomentar y promover en los aprendizajes valores familiares, como la "maternidad y paternidad responsable"125. De esta manera, es posible evidenciar que no existía una preocupación a la fecha relativa a las cuestiones de carácter estructural y cultural que emanan de las diferencias sexuadas entre los y las estudiantes, ni de la importancia de una formación profesional docente atenta a esas diferencias.

Sin embargo, como a toda puesta de sol sucede un amanecer, vemos desde hace algunos años renacer en la sociedad civil un crisol de iniciativas educacionales tendientes a eliminar todo sexismo y diferencia de género en educación. A dotar de humildes aportes interpretativos para esos movimientos ha querido contribuir el siguiente artículo.

\section{Bibliografía}

Aldo Panfichi, Sociedad civil, Esfera pública y democratización en América Latina: Andes y Cono Sur, p. 297-328, Fondo de Cultura Económica Ltda., México D.F, 2002.

Andrea Zamora, "La mujer como sujeto de la violencia de género durante la dictadura militar chilena: apuntes para una reflexión", Nuevo Mundo Mundos Nuevos [en línea], 2008. Antonio Viñao, "La historia de las disciplinas escolares", Historia de La Educación, 25, Universidad de Murcia, 2006, 243-269.

Basil Bernstein, Pedagogía, control simbólico e identidad, Madrid, Morata, 1996.

Miguel Arroyo Currículo, Território em Disputa, Petrópolis, Editora Vozes Ltda, 2013.

C. Dides, C. Benavente C, I. Sáez, L. Nicholls, "Educación Sexual en Chile. Implementación de la Ley 20.418." Boletín 4, UNFPA y Universidad Central de Chile, 2012.

Carmen Godoy Ramos, Géneros, Sexualidad/es y Nación en el Chile Postdictatorial 19902008, Tesis para optar al grado de Doctora en Estudios Latinoamericanos, Santiago de Chile, Universidad de Chile, 2011.

Comité Permanente de la Conferencia Episcopal, Acerca de la Educación Sexual, 10 de septiembre 1996.

Cristian Cox, Politicas educacionales en el cambio de siglo. La reforma del sistema escolar de Chile, Santiago de Chile, Editorial Universitaria, 2003.

Cristian Cox, "Construcción política de reformas curriculares: el caso de Chile en los noventa". Profesorado. 10, 2006.

Díaz, Patricia, El género de la transición. Una historia de las políticas públicas con perspectiva de género en los gobiernos de la Concertación. Memoria para optar al título profesional de periodista, Universidad de Chile, Santiago de Chile, 2012.

Elizabeth Guerrero Caviedes, Patricia Provoste Fernández y Alejandra Valdés Barrientos,

125 Congreso Nacional de Profesores, 1997. 
"La desigualdad olvidada: género y educación en Chile", Equidad de género y reformas educativas, Santiago de Chile, Hexagrama Consultoras, FLACSO, Instituto de Estudios Sociales Contemporáneos, 2006.

Elizabeth Guerrero, “Transversalización de la perspectiva de género en Chile: en la búsqueda de la equipad", X Congreso del Centro Latinoamericano de Administración para el Desarrollo, Santiago de Chile, 2005.

Encuentro de la Concertación de Mujeres por la Democracia, Informe Final, Santiago, El Canelo de Nos, septiembre 1990.

Fraser, Nancy, Iustitia Interrupta. Reflexiones críticas desde la posición 'postsocialista', Siglo de Hombres Editores, Universidad de Los Andes, Colombia, 1997.

J. Bernal, H. Bonacic, V. Edwards, R. Méndez, J. Guler. “Encuesta sobre conducta sexual de adolescentes. Proyecto FONDECYT", La Segunda, marzo 1992.

Jaime Fernández, JOCAS: La punta de un Iceberg, Santiago, Editorial PATRIS, 1996.

Jorge Ochoa, "La sociedad vista desde los textos escolares”, CIDE, Santiago, 1983.

José Gimeno Sacristán, Saberes e incertidumbres sobre el curriculum, Madrid, Ediciones Morata, 2010.

José Morán, "Feminismo, Iglesia católica y derechos sexuales y reproductivos en el Chile post-dictatorial”, Estudios Feministas, 21:2, Florianópolis, 2013, 485-508.

José Olavarría y Rodrigo Molina, "Embarazos en adolescentes, vulnerabilidades y políticas públicas", Polis, 11:31, Santiago de Chile, abril 2012, 411-433.

José Olavarría, “La política de educación sexual del Ministerio de Educación de Chile. Consideraciones para una evaluación", Seminario Internacional Equidad de Género en las Reformas Educativas de América Latina, Hexagrama, 2005.

Josefina Rossetti, "Educación y subordinación de las mujeres", Eduardo García Huidobro (ed.), Escuela, calidad e igualdad. Los desafios de educar en democracia, CIDE, 1989.

Leo Arenas, Jennifer Durán, Claudia Dides, Constanza Fernández, Primer informe Salud Sexual y Reproductiva y Derechos Humanos en Chile.

Leonardo Arenas, Historia de la educación sexual en chile (1990-2014): enfoques y perspectivas, Tesis para optar al grado de Magíster en Educación, Santiago de Chile, Universidad Academia de Humanismo Cristiano, 2015.

Manuel Canales, Gilda Aceituno, Germán Morales, Irma Palma y Juan Jiménez, Evaluación Jornadas de Conversación sobre afectividad y sexualidad, Santiago de Chile, Coordinación Interministerial SERNAM-MINSAL-MINEDUC-INJ, 1997.

Marc Depaepe, Vieja y nueva historia de la educación, ensayos críticos, Barcelona, Octaedro, 2006.

Marcela Ríos Tobar y Lorena Godoy, ¿Un nuevo silencio feminista?: la transformación de un movimiento social en el Chile post-dictadura, Centro de Estudios de la mujer, Santiago, Editorial Cuarto Propio, 2003.

María de la Luz Silva, "Mujer y participación política", En Participa, "La identidad femenina en situaciones de conflicto y poder", Editorial Andrés Bello, Santiago, 1992.

María de la Luz Silva, "Perspectiva de género en las políticas educacionales", PIIE, Educación y transición democrática. Propuestas de políticas educativas, Santiago de Chile, octubre de 1989.

María Inés Picazo, "La reforma del currículo escolar en Chile: entre tensiones creadoras y 
consenso necesario", Pensamiento Educativo, 40:1, 2007, 313-333.

María Inés Picazo, Las políticas escolares de la Concertación durante la transición democrática, Santiago de Chile, Ediciones UDP, 2013.

MINEDUC, Establece objetivos fundamentales y contenidos mínimos obligatorios para enseñanza media y fija normas generales para su aplicación, Decreto 220, 04 junio 1998.

MINEDUC, Hacia un Política de Educación Sexual para el Mejoramiento de la Calidad de la Educación, Santiago, 1993 (reedición 2001).

Naciones Unidas, Informe de la Conferencia Internacional sobre la Población y el Desarrollo, El Cairo, Egipto. 1994.

Paola Abatte, Paula Arriagada y Germán González, Texto guía para la autogestión de Jornadas de Conversación sobre Afectividad y Sexualidad, 1999, pp. 17-18.

Patricia Díaz, El género de la transición Una historia de las políticas públicas con perspectiva de género en los gobiernos de la Concertación, Memoria para optar al título profesional de Periodista, Santiago de Chile, Universidad de Chile, 2012.

PIIE, Ruptura y construcción de consensos en la educación chilena. Santiago de Chile, PIIE, 1988, p. 34.

Programa de Gobierno Concertación de Partidos por la Democracia, Sección "Incorporación plena de la mujer y protección de la familia".

Programa de Naciones Unidas para el Desarrollo (PNUD), Informe de Desarrollo Humano. Género: los desafíos de la igualdad. Santiago de Chile, 2010.

Sebastián Neut, "Prácticas y discurso intelectual en ONG's educacionales opositoras a la Dictadura chilena. Los casos del CIDE y PIIE", Revista Izquierdas, 42, octubre 2018, 198-223. Sebastián Neut, "El conocimiento escolar en disputa en Chile: el caso del currículum fracasado de 1992", Currículo sem Fronteiras, v. 18, n. 2, maio/ago. 2018, 614-638.

Sebastián Neut y Marco González, "La noción de políticas públicas durante los gobiernos de Concertación. La reflexión de algunos intelectuales del periodo y consideraciones para una discusión histórica del problema", Cuadernos de Trabajo Social, 17, enero 2018, 103-124. Ramiro Molina (ed). Adolescente embarazada en Chile. Diagnóstico de la situación 1991, SERNAM, UNICEF, CEMERA, 1991.

Raymond Williams, La larga revolución, Buenos Aires, Nueva Visión, 2003.

- REVEDUC, Revista Ministerio de Educación, 1991, 1992, 1996.

- Revista Docencia, 1996-1998.

- Revista Servicio, 1992.

- SERNAM, Comentarios a Documento Objetivos Fundamentales y Contenidos Mínimos, Santiago, Julio 1997.

- SERNAM, Plan de Igualdad de oportunidades entre mujeres y hombres 2000-2010. Evaluación primera fase, Santiago de Chile, 2005.

- Sonia Montecinos y Josefina Rosseti, Tramas para un nuevo destino: Propuestas de la Concertación de Mujeres por la Democracia, Santiago, Concertación de Mujeres por la Democracia, 1990.

- Tomás Tadeu De Silva, Documentos de identidad. Una introducción a las teorías del currículum, Belo Horizonte, Auténtica Editorial, 1999.

- Verónica Valdivia Ortiz de Zárate “LLas "Mamitas de Chile"? Las mujeres y el sexo bajo 
la dictadura pinochetista", Julio Pinto Vallejos (ed.), Mujeres: Historias chilenas del siglo XX, Santiago de Chile, LOM, 2010.

- Virginia Guzmán, Sandra Lerda y Rebeca Salazar, La dimensión de género en las políticas públicas, Centro de Estudios de la Mujer (CEM), Santiago de Chile, 1994.

- El Mercurio, 1992, 1996.

- La Nación, 1992, 1996.

- La Segunda, 1996.

- Sesiones cámara de Diputados, septiembre-octubre 1996. 